\title{
Factors Affecting Difficulties in Learning Mathematics by Mathematics Learners
}

\author{
Bed Raj Acharya \\ Central Department of Education, Department of Mathematics Education, Tribhuvan University, Kathmandu, Nepal
}

\section{Email address:}

acharyabedraj@yahoo.com

\section{To cite this article:}

Bed Raj Acharya. Factors Affecting Difficulties in Learning Mathematics by Mathematics Learners International Journal of Elementary Education. Vol. 6, No. 2, 2017, pp. 8-15. doi: 10.11648/j.ijeedu.20170602.11

Received: September 16, 2016; Accepted: October 21, 2016; Published: May 17, 2017

\begin{abstract}
This article explores the adversities faced by public school students in learning mathematics in their leaning context. The main purpose of this study was to explore the causes of learning difficulties in mathematics. The design of the study was qualitative. Classroom observed / practices of three schools of Arghakhanchi district and interview taken to the research participants to achieve the research objective. It discussed the different data texts from the potential participants. From the analysis and interpretation of data, it concluded that students, teachers and parents have to play an important role as key and provider of sound environment for improvement of pass rate respectively. Teachers lack of linkage between new mathematical concept and previously learned mathematics structure, mathematics anxiety, negative felling of mathematics, economic condition and their educational backgrounds, school management system, lack of infrastructure of school and lack of regular assessment system of school are main causes of difficulties in learning mathematics.
\end{abstract}

Keywords: Parental Supports, Environmental Related Factors, Teacher Related Factors, Causes, Participation, Affecting, Difficulties

\section{Introduction}

Mathematics is the one of the most importance subject in our human life. Without the knowledge mathematics, we can say nothing possible in the world. Now a day's mathematics is globally accepted but locally useless. Mathematics has been accepted as an importance component of formal education from ancient period to the present day. Our history shows that ancient scholars developed mathematics practically being obliged day-to-day problem. In the ancient period, mathematics has developed by great shepherds. Mathematics is the body of knowledge in the area of science and technology. The subject mathematics is beautiful and interesting because its own symbols, language, terms, technology etc. Mathematics is being main part of human lifestyle. In the world, each society has their own mathematical languages, terms, symbols, counting system in different countries like as Chinese, American, Japanese, Arabian etc.

The National Research Council purported that students learn mathematics well only when they construct their own mathematical understanding and that this understanding requires them to examine, represent, transform, solve, apply, prove, and communicate [10 ]. Mathematic is the significant subject in our human life. As mathematics has emphasized like language most of students have been failed in mathematics as a difficult subject and majority of students fail in mathematics.. By this problem the great deal of time, money effort and man power of the nation subject matter, curriculum refineries available problem solving method extra activities affect to study mathematics in every sectors, Educationists as well as state are facing the challenges with the problems of failure in SLC examination in mathematics. The students are suffering by various problems and they are facing the challenging of SLC examination being failure in mathematics. What are the main influencing factors to learn mathematics? So, it try to answer the questions like, What are the causes of difficulties in learning mathematics? Question like this occurs it was motivated to carried out this research.

\section{Objective}

The main objective of this paper is to find out the factors affecting difficulties in learning mathematics. 


\section{Methodology}

The ontology in this study is that there are multiple realities. The epistemology of this study is that knowledge obtain from the mathematics learners is subjective. The research methodology it has chosen is qualitative. Qualitative technique is a form of inquiry that explores phenomena in their natural setting and uses multi-method to interpret, understand, explain and bring meaning for them [5]. Qualitative research is multi methods, usually studies in real world situation and it is more naturalistic [1]. Research design is also a strategies plan of the project that sets out the broad structure of the research. It is necessary requirement for all research of whatever style [5]. It is concerned with what, whom, how, and why? The question 'how to observe?' is this phenomena directly concerned with the methodological aspect of the research design. Research design, paradigm, or approach is a way to think about doing research. According to Creswell [6] there are three research designs- qualitative, quantitative and mixed-method. In this study, it was used qualitative research design. The qualitative research used the context and setting to search for a deeper understanding of the person being studied [4]. In this regard, [8] explain:

Qualitative research is multi-method in focus, involving an interpretive, naturalistic approach to its subject matter. This means that qualitative researchers study things in their natural settings, attempting to make sense of or interpreted phenomena in terms of the meanings people bring to them ( $p$. 5).

Therefore, it was attempted to visualize the interpretation of their world of the research participants. Then I interpreted the meaning generated by my participants. Thus there exists multiple interpretations of social realities from the perspectives of participants and me as a researcher.

Qualitative research is a means of exploring and understanding the meaning of individuals or group ascribed to a human problem [8]. It is a procedural plan adopted by a researcher to answer research questions and achieve the aims of research. It is flexible, emergent, iterative and dynamic. Qualitative research is a situated activity that locates the observer in the world. It consists of set of interpretive materials practices that make the world visible and transform the world. They turn the world into a series of representations, including field notes, interviews, conversations, photographs, recordings and memos to the self. At this level, qualitative research involves interpretive, naturalist approach to the world [8].

A qualitative research begins with assumptions, a worldview, the possible use of theoretical lenses, and the study of research problems inquiring into the meaning of individuals or groups ascribed to social or human problems [7]. While conducting the qualitative research the researchers use an emerging qualitative approach to inquiry- the collection of data in a natural setting sensitive to the people and places under study and data analysis that is inductive and establishes patterns or themes. There are different characteristics of qualitative research. According to [6] the main characteristics of qualitative research are as follows:

(i) Natural setting

(ii) Researcher as key instrument

(iii) Multiple sources of data

(iv) Inductive data analysis

(v) Participants' meanings

(vi) Holistic account

(vii) Research process and strategy are flexible, emergent and iterative

The purpose of qualitative inquiry is to gather nonnumerical data to help explain or develop a theory about relationship. In this regard, [4] suggestion about qualitative research is that qualitative research offers opportunities for conducting exploratory and descriptive research that uses context and setting to search for a deeper understanding of the persons being studied (p. 247). They further suggest in qualitative research that all the activities done by the researcher as collecting and analyzing data, elaborating the theories, focusing and refocusing the research question, threats of trustworthiness go together simultaneously. Qualitative research relies primarily on the collection of primary data. In this context, qualitative research is a field of inquiry that crosscuts disciplines and subject matters [8]. Qualitative research is oriented towards analyzing concrete cases in their temporal and local particularly starting from people's expression and activities in their local context [9].

The site and sample it has selected purposively are Arghakhanchi district and mathematics teachers their children, head teachers and parents. During the study, it has not disclosed the participant's real name following the research ethics. Through interview of children, mathematics teachers, head teachers and classroom observation of 30 days, I have generated the data. The concept of observation, indicates that data should enable the researcher to enter and understand the situation that is being described (Patton, 1999). It was asked open ended questions to explore what factors affecting difficulties in learning mathematics by mathematics learners. It analyzed the data with the help of following themes which emerged in the field and deduced meaning inductively.

\section{Students Related Factors}

Student's related factor is one of the important aspects of high fail rate in mathematics plays vital role in a teachinglearning process. Without students interest in the teachinglearning actives there is no possibility to achieve knowledge in subject matter. Student's achievement depends on their need, interest, practices and seriousness in subject matter. Students related factors include mathematics anxiety, prior knowledge of students and student's labor in learning mathematics. Thus the collected data were analyzed and interpreted on the line of following sub-heading.

\subsection{Mathematics Anxiety}

Mathematics anxiety is a one of the important aspect of 
student's related factors in learning mathematics. Mathematics anxiety is a negative feeling to mathematics learning process. When examining student's problems in mathematics anxiety as a feeling of tension, apprehension, or fear that interfere the mathematics performance. Mathematics anxiety refers to forget and confidence in subject matter. It affects the students' mathematics learning process. Also it affects the subjects pass rate in mathematics in SLC. In the line with discussion, the following views of students were stated here related to mathematics anxiety.

I asked some participants among them Kalpana said thatmathematics is only for clever ones. It is difficult to learn, only talent students were able to read mathematics. I am also weak in mathematics. And in the first class, our mathematics teacher discourages us by predicting negative aspects and made us afraid of this mathematics. Teacher also said us it is very hard to study so, I did not choose mathematics (Interview recorded; 17 September, 2014).

Bikash was replied as my brother said me that mathematics had several formulas and these formulas always necessary to remember for learning mathematics and difficult to understand so I feel that mathematics is a difficult subject. And I hesitate to join mathematics class due to mathematics anxiety. The views of mathematics teachers and head teachers regarding above response are as mentioned below (interview recorded; 23 September, 2014).

The above information student and mathematics teacher discussion about the anxiety of mathematics indicated that mathematics has several formulas which are very hard to understand and not related to other subjects. Students were feeling mathematics has abstracts subject.

Among the above students Sarita said that mathematics teachers said me that mathematics has several formulas. Many students are not ready to learn this formula student's fear in learning mathematics. So the students cannot able to read mathematics the head teacher said me that I think mathematics is not related to other subject students were feeling abstract to learn the mathematics from lower level. So students do not pass in mathematics that's why I really don't like mathematics when mathematics teacher teach mathematics in my class I feel very nervous and when finish the class and teacher may go out of class. (Interview recorded; 19 September, 2014).

The views of parents towards response were mentioned below

The some parents say in other society, most of the people feel mathematics is difficult subject then other so I suggested my son to study economics subject instead of mathematics (interview recorded; 23 September, 2014)

On these above views of the students, mathematic teachers, head teacher and parents indicated that mathematics is a difficult subject. Mathematics is only for cleaver students. Student feel mathematics is complex subject. It has no direct use to daily life. And it is not concern with other subject. Therefore, it was make anxiety to learn mathematics for students. Mathematics anxiety directly affects the students to learn well. Lim, Chip, Sam emphasis that students' anxiety of mathematics is responsible for students fail in mathematics. Similarly they argue that negative explanation about mathematics from the teacher's side parents and other person created fruition and anxiety and ready to learn meaningful way.

\subsection{Prior Knowledge of Students}

Prior knowledge of students is another aspect of student related factors which means the previous knowledge of the students towards mathematical contents. The basic knowledge of mathematics in lower secondary level is the key factors which determined good performance of the students or not at great $\mathrm{x}$. it is also determine student's performance in the further study. Mathematical preknowledge is the infrastructure as well all round development of students in the mathematics sectors. Those students who have lack of sufficient prior knowledge did not want to learn and could not get success in the further level. It is responsible for students fail in mathematics in all school secondary level. In the line with discussion the following views of students were stated here related to prior knowledge of students

The above view of student's emphasize students have not sufficient previously learned mathematical knowledge. The students cannot assimilate of relating new mathematical concept and principle to previously learned mathematical structure.

The mathematics teacher asked to the students about the pre knowledge of this topic but every student were silent and nobody answered this question and although they have shyness and not to be frank with teacher and students they seems like they are afraid with teacher and if I answered somedody will laugh and hesitated me after finished the class Arjun said me who is the one participant of this research. Lawati said: I had main problem to learn mathematics in the lower secondary level. Mathematics course were not finished in time. Also I know about use of mathematics. So I actually not like to learn mathematics when I face to problem of mathematics it is began to headache (interview recorded; 23 September, 2014).

The head teacher say most of the students promoted in the subject of mathematics at lower level without concept of mathematics, so they were unable to perform good in mathematics similarly, mathematics teacher say in the lower secondary mathematics curriculum were not include the sufficient basic concept of mathematics. Students feel mathematics is new one and difficult subject. It is not related to the students behavior life and it is not relevant with the locality of Humla district there student face language problem specially the students background is very critical stage for survivable in the society. And many study time they spending to mention the footing process. It is being grate problem. Like in the study time they go to collect herbal valuable plants and grazing the cattle in the forest to get a little amount of money. Basically, students are not serious in basic rules and properties of mathematics. So students did not 
pass in mathematics. The support view of parents regarding above response is given as my children always fail in mathematics in lower secondary level. So, I did not recognize why he fail in mathematics.

The above mentioned view of students, mathematics teachers, head teacher and parents were indicated that prior knowledge of mathematics is importance for the betterment of students pass in mathematics. The head teacher say students were promoted unnecessary without knowing the concept of mathematical knowledge in the lower level and mathematics teachers say students have no sufficient basic knowledge in mathematics in this time that's the region students did not pass in mathematics. These all response indicated that the students cannot able to assimilate or relating new mathematical concept and principal to previously learned mathematical structure.

In regarded, Albert Bandore's social learning theory emphasizes the importance of observing and modeling the behaviors, attitudes, and emotional reactions of others. [2] states: "Learning would be exceedingly laborious, not to mention hazardous, if people had to rely solely on the effects of their own actions to inform them what to do. Fortunately, most human behavior is learned observationally through modeling: from observing others one forms an idea of how new behaviors are performed, and on later occasions this coded information serves as a guide for action." (p22). Social learning theory explains human behavior in terms of continuous reciprocal interaction between cognitive, behavioral, an environmental influences. The component processes underlying observational learning are attention, including modeled events distinctiveness, affective valence, complexity, prevalence, functional value) and observer characteristics (sensory capacities, arousal level, perceptual set, past reinforcement), retention, including symbolic coding, cognitive organization, symbolic rehearsal, motor rehearsal), motor reproduction, including physical capabilities, self-observation of reproduction, accuracy of feedback, and motivation, including external, vicarious and self reinforcement.

Because it encompasses attention, memory and motivation, social learning theory spans both cognitive and behavioral frameworks. Scope/Application: social learning theory has been applied extensively to the understanding of aggression [2] and psychological disorders, particularly in the context of behavior modification [2]. It is also the theoretical foundation for the technique of behavior modeling which is widely used in training programs. In recent years, Bandura has focused his work on the concept of self-efficacy in a variety of contexts. Example: The most common (and pervasive) examples of social learning situations are television commercials. Commercials suggest that drinking a certain beverage or using a particular hair shampoo will make us popular and win the admiration of attractive people. Depending upon the component processes involved (such as attention or motivation), we may model the behavior shown in the commercial and buy the product being advertised. Hence, the role of prior knowledge of mathematics is very important aspect for students pass in mathematics in SLC examination.

\subsection{Lack of Student's Labour}

It is another and importance aspect of students related factors that affect in students low pass in mathematics. Mathematics is needed practice which has different theory and several formulas. So learning of mathematics, students should be manages extra time for practice. Generally mathematics achievements determine students labour in present situation; students are not laborious in mathematics learning. Consequently, mathematics achievement of students was diseasing. It was affect on student slow pass in mathematics. Student's labor is responsible for students following views of mathematics teachers were stated here related to students labor in learning process of mathematics.

Some mathematics teacher says students do not try to learn mathematics and do not want to do extra labour. They are engage in unnecessary task in the class room during learning process. Mathematics is more complex subject to understand then other subject. But students are not serious to do hard labor in the process leaving mathematics but in reality students did not give more time to learn mathematics the supported views of head teacher towers above response as given students aim to pass the exam without doing hard labor. Than tend to spend few time to prepare exam. So, most of the students choose economics and geography instead of choosing mathematics and another support view of parents towards student's labor in learning mathematics is given as our economic condition I $\mathrm{s}$ weak because of traditional agriculture. Our children are bound to help us in farming. Children have no time to learn in home.

The above view of mathematics teacher, head teacher and parents indicate that most of the student did not have sufficient time to learn mathematics. Students are engaged in unnecessary task instead of teaching activates. Some students are busy in their house hold work because they are busy in house hold work and farming. Students have no time in their home to learn mathematics. They want to pass the exam without doing hard labor and practices in mathematics. Consequently, students did not interest to study mathematics. In this regards Thapa (2011) argue that students should ready for extra practices for batter performance in mathematics. Those students are not manage extra times and ignore for doing practice. Obviously, they would be weak in mathematics and they are unable to pass in mathematics.

\subsection{Parent's Supports}

Parents' support is one of the important aspect of parents factors studying mathematics. Parents who play supportive role to their children learning and it is helpful for improve students' achievement and changing behavior parents' support can play a vital role at all stages of education. Parents achieve support for their child's learning can make good achievement in education. School can befit from positive partnership with parents by involving decision making 
process which affected students pass in mathematics. The supportive views respondents on this problem are as follows.

Akarti and Bikranta said that our familes economy condition very low class regularly and my family can not able to support in mathematics learning. So I did not study mathematics very well. Others students replied as I have no any support in my home to learn mathematics. So I said no study mathematics. Another support views of head teacher regarding parents support in their children as given most of the students of our school are from low economic and uneducated family background. The children of those families are busy in household work instead of doing homework. Students become weak in mathematics and they are bounded in other subject. The views of some parents regarding above response as mentioned as I am illiterate man I don't know what mathematics is and what others subject is. Also I cannot able to support in child learning. Other parent replies as in our family there are no any people to support learning mathematics. (interview recorded; 28 September, 2014).

These above views represent the real situation of students. Most of the parents of public secondary school they are illiterate. They cannot able to support children in learning mathematics. The children of those families are not interested to learn mathematics due to family support. Consequently, students did not Pass in mathematics in secondary level. So, students pass in mathematics is low Ghimire 2011 argue that family support play vital role in children education. Students need and interest are determined by their family support. In this regard Ausuble argue that students learning achievement depend on their need and interest. The researcher concluded that those students who could not take support from their families. They did not pass in mathematics. Hence one major cause of low students passes rate mathematics in school level.

\section{Teacher Related Factors}

Teacher related factors are the one aspect of low pass rate in mathematics at secondary level. Teacher is a person who provides education for students individually and motivate for teaching learning activities. The children's education depends on the role of teacher in teaching learning activities. Positive attitude of teacher creates positive direction to students for learning mathematics. In this section the researcher emphasized on the teacher factors include motivation towards students and assessment system of student which affected students pass in mathematics from Humla district. Among different factors, affecting mathematics learning one of the teacher related factor is motivation.

Motivation is the one important factor of high failure in mathematics. Motivation is the internal and external factors that stimulate desire and energy in students to be continually interested and committed to learn something. The process of motivation stems from stimulation which is turns followed by an emotional reaction that lead to a specific behavior response. In the mathematics classroom, motivation refers an individual activity of students to learn mathematical knowledge. Positive motivation is stimulate the desirable behavior of students. Positive attitude towards mathematics play valuable role in learning mathematical knowledge in all stages of education. But in this study it found that stakeholder cannot able to provide counseling towards mathematics. That's why students have been mathematics anxiety existed yet. So, motivation and counseling are play a vital role in students pass in mathematics. In the line with discussion, the students share their view as

Some students say our mathematics teacher said us mathematics is so difficult. Also they cannot give positive direction to learn mathematics. That's why we are weak in mathematical knowledge. So I did not choose mathematics. Other students replied as I don't know what will have if I admit in mathematics? Another supported views of head teacher regarding motivation as given we are not able to provide counseling and motivation to study mathematics because we have no sufficient infrastructure and learning equipment. So student's always feel mathematics is difficult.

On the basic of the above mentioned views of students and head teacher, teacher cannot create positive attitude towards mathematics. School administration also did not motivate to students for pass in mathematics. Students have negative feeling in mathematics and they feel it is difficult to learn mathematics. In this regard Asubel's theory argues that students should be motivated to learn mathematics in meaningful way. Supporting this view [12] claims that the role of teacher will be mentors and role of students is active participation in teaching process the mathematics learning become meaningful. Poorly motivated students may not learn mathematics. So students did not pass in mathematics lack of motivation and counseling. Hence one cause of low pass rate of students in mathematics is lack of counseling and motivation to students.

\section{Environment Related Factors}

An environmental factor is very important aspect of students high fail rate mathematics. In this study, environment related factors refer teaching learning environment and home environment. Teaching learning environment indicated that the environment inside of classroom. Home environment indicate family environment. These different environmental factors determine the students' activities in learning. Also learning achievement of students guides their families' environment and school environment in this section, the researcher emphasized on environmental factors include teaching learning environment and home environment of student which affect on students pass in mathematics. Thus the collected data were analyzed and interpreted on the following headings

\subsection{Teaching Learning Environment}

Teaching learning environment is next important aspect of environmental factor. It refers to show and where students 
gain a mathematical knowledge and how they change their behavior. In the teaching learning process, teacher should manage the suitable environment for learning mathematics. Teacher should address students need and interest. Also teacher motivate to students in the classroom. Schools admiration should manage child friendly environment for better performance of students. Child friendly teaching learning environment has played important and vital role in students learning process. Teaching learning environment is responsible for students pass in mathematics. On the basis of these situations the researcher concerned with students, mathematics teacher, head teacher and parents.

In the line with discussion, the following views of students were share related to teaching learning environment.

Some students say our teachers teach us mathematics. But I afraid with teacher. Teacher give threaten to us to memorize mathematical formula. So I chosen economic subject supported views of mathematics teacher towards teaching learning environment in classroom as given we cannot able to teach in the classroom with students center teaching methodologies and technical methods due to large number of students and lack of required material another supported views of head teacher towards teaching learning environment of school as given we cannot manage trained and professional teacher due to poor economic background of our school. School has limited sources and teachers. So, students may be weak in mathematics. And they are chosen other subject instead of mathematics to do better result.

On the basis of above mentioned views of these respondents, teachers apply traditional teaching learning, methods. Teacher did not address students need and interest in the classroom. There is no child friendly environment in the classroom. School has limited sources. Numbers of students are many, so the teacher cannot use students oriented teaching learning in classroom in spite of his will. School has been bound in traditional teaching methods. In this argument [1] argues that students pass in mathematics depend on teacher attitude, teaching learning environment and physical structure of school. Those school did not apply these things obviously students pass rate getting low. But, Ausubel's argue that learning cannot be meaningful teach the students themselves prepared. However this matter cannot found in this study. In this study, these problems had in case school. So students pass in mathematics at public secondary level is low. Hence one cause of law students passes in mathematics in secondary level and learning environment.

\subsection{Home Environment}

Home environment is another important aspect of learning mathematics. Home is first school of child and mother is first teacher. All children education depends on their home environment. Good home environment enhances students' achievement in mathematics. Uneducated person unaware about the importance of mathematical knowledge in their life and they cannot force to learn mathematics to their child. Students pass in mathematics from all schools depends on their home environment and they learn everything from their family member characters and their society behaviors in this study parents are not aware in child education. On the basis of these situations the researcher concerned with students, mathematics teacher, head teacher and parents. In the line with discussion, the following views of students were stated here related to home environment.

Some students say we have no any support from my home to learn mathematics. Because my parents were busy in farming and my families are illiterate I have supported in household work. Another supported views of mathematics teacher towards home environment of students as given students cannot give more time to learn mathematics because they are busy in household works. And parents have no concern about their child learning. So students were weak in mathematics. Students bound in other subject instead mathematics.

Similarly, the supported views of head teacher towards home environment of students are given as we are illiterate and we cannot support to child education. So it did not prescribed him to pass in mathematics, another view of head teacher is most of the students our school are from poor and uneducated family background. The children are busy in household work instead of doing homework so that they become weak in mathematics and they are bounded in other subject.

On the basis of above mentions view of students' mathematics teacher, head teacher and parents, students are busy in their household work. Students cannot read in home. Students have no any support person in their home to learn mathematics.

\subsection{Economic Status of Parents}

Economics status of parents is one an important aspect of parents factor in studying mathematics. Economic status of parents is determining their children education. Many literature shows that the economic status of the parents directly affects the Child's learning. In the above view related literature also indicated that situation. Those parents who have good economic condition, most of their children's education is good because they can manage tutor in home as much as possible. But these conditions we cannot found in poor family. In this study the researcher found that the economic condition or status of most of the families have low. The different views on this problem are as follows.

Hemanta said; my family economic condition is poor. I could not able to take extra class for mathematics. So I am less interested in mathematics subject. Another supported views of mathematics teacher regarding economic condition of the parents is given as sometimes I manage the tuition class for weak students but most of the students absents due to lack of fees for tuition class. In the same way head teacher replied most of the students of our school were from low economic base and uneducated family background. The children of those families are busy in household work instead of doing homework so that they become weak in mathematics and they are bound to 
choose other subject on this same problem parents replied as our economics condition is very low because of traditional agriculture system. Our children are bounded to help us in farming. They have no sufficient time to learn mathematics. Also I did not able to manage them tuition fees for extra class. In this study the teacher took interview with 12 students in different aspects this interview related to why students said not interesting to learn mathematics at lower secondary level. In this way the teacher asked the different question to students in interview period. The researcher found one especial case that affect in studying mathematics. The theme of this special case was given below.

One day the researcher went to one of the key respondent's house for purpose of taking interview with parents. The researcher found that the economic condition of family was low economic status. The main economic source of this was labor and agriculture and grazing cattle, collecting valuable medical herbs. Which is insufficient to fulfill our basic needs? It is very hard to by any kind of mathematics materials because of desperate poverty in family. Students said, I would do very well in mathematics but due to our low economic condition. We have hand to mouth problem. Students say, I am going to read mathematics at secondary I felt very difficult and I am not able to understand the basic concept of mathematics. The researcher asked why did not read mathematics very well. Students replied our mathematics teacher said us every student bring sufficient calculator for doing calculation. But, I did not manage calculator at this time.

I am feel hesitate to read mathematics. So I came back to read mathematics.

The above view indicated that parents are engage in farming and house hold work all most time. They have no any income sources. They have solved only hand to mouth from their morning to evening their farming. So, they have no sufficient amount of money to manage the fees required for extra class. Children cannot be able t pay tuition fee for more study. And lack of motivation of parent's and education of parents are played a vital role in studying mathematics. Consequently, they are failing in mathematics. In the above review, it clear that lack of economic condition of family affects on students fail in mathematics. In short the teacher declared that one aspect of law pass of students in mathematics is lack of money to pay tuition fees. So students had chosen other subject instead of mathematics.

\section{Parents Related Factors}

Parents related factors are the one of the important aspect of students pass in mathematics. Parents role are play important in of their children education. Almost children education depends on their family background and parent's economic status. The home is the first school o the children and second is school. Home environment affects directly on child school of the children education. Consequently, it is determine the mathematics learning of children. In this section, the researcher emphasize on educational background of parents, economic status o parents and support of parents. Thus, the collected data were analyzed and interpreted on the following heading.

Educational backgrounds of parent are one and important aspect of the parents play a role for studying mathematics. The education of child does not depend on only teacher role but also depend on their parents awareness interest and knowledge about handing and guiding their children at home. Parents can introduce and teach values are depending on their parents' education. Uneducated person do not know important of mathematics knowledge in their life and they cannot force to learn mathematics to their child. The researcher collected the data about educational background of the parents. According to school documents among of 12 parents there are 11 parents are uneducated and only one parent is educated and he is teacher of Nepali subject also.

In the line which discussion the following views of students were stated here some students said that father and mother both are uneducated. Parents cannot able to support me to learn mathematics. But I must be engaged to support in house hold work. So I cannot study mathematics very well. The supported views of head teacher regarding above response are given as most of the students of our school are from poor and uneducated family background. The children of those similes are busy in household work instead of doing homework. So that they become weak in mathematical knowledge and they are bounded to choose other subject the supported views of parents, regarding above response is given, as I am illiterate. I don't know what mathematics is and what other subject is. I cannot be able to support in children learning. My children always go to school but I don't know what they do and learn in school (interview recorded; 27 September, 2014).

The above view of students, teachers and parents indicated that all most the parents are illiterate. Students cannot get any support from their family to learn. Students also feel mathematics is difficult subject. Parent's attitude is negative towards mathematics they do not know important of education especially mathematic. They cannot able to manage time for learning in home due to farming occupation. But one educated parent says I want to teach mathematics to my child if he wanted to learn higher level education. But he is very weak in his study I think he will not study mathematics well in his future. Consequently students might not study mathematics very well if he choose mathematics it is sure that he will not do well performance in mathematics because there are many factor trapping him. Hence, one case of low students pass in mathematics in all students of secondary level is uneducated background of parents

\section{Result}

On the basis of analysis and interpretation of the data, the major findings of the study are as follows:

- Mathematical anxiety, lack of interest and negative felling towards mathematics, it makes difficult to learn 
mathematics.

- Lack of prior knowledge of the student creates problem to study mathematics.

- Lack of student's labor in learning mathematics learning.

- Lack of parent's awareness, interest of the subject matters affects their children to study mathematics.

- Due to low economic condition of students, they have to engage their household work to fulfill their daily needs. So students are not interest to study mathematics.

- The students who did get support and inspiration from their parents students result is better.

- Lack of motivation and counseling crates misunderstanding to study mathematics.

\section{Conclusion}

It came to the conclusion that there are a number of intermingled factors that are detrimental to low performance of public school students in mathematics. The under recognition of students' need and interest with their preexisting level of knowledge and skills towards mathematical concepts are the major determining factors of lower achievement in mathematics. Student's interest and positive feeling of mathematics increase the pass in mathematics. The parents' meaningful engagement with quality time for helping to learn to the students at homes, due to poor economic is another pertinent cause of their low performance. Negative explanation about mathematics from the teacher's side parents and other person created frustration and anxiety in mathematics students; pass in mathematics depends on student's labour in learning mathematics. Lack of parent's awareness, interest of the subject matter affects their children to study other subject. So, it should be eradicate barriers factors influencing to learn mathematics and make mathematics learning enjoyable in our context.

\section{References}

[1] Acharya, B. R. (2017). Diversity in mathematics education, Kathmandu: Pinnacle publication Pvt. Ltd.

[2] Bandura, A. \& walters, R. (1963). "Social learning and personality development. New York: Holt Rinehart \& Winston.

[3] Bandura, A. (1977).Social learning theory, New York: General learning press.

[4] Best, J., \& Kahn, J. (1999).Research in education ( $7^{\text {th }}$ ed.).New Delhi: Prentice-Hall.

[5] Brewer, J. D. (2005). Understanding social research. In A. Bryman (Ed.), Ethnography. Philadelphia, USA: Open University Press.

[6] Creswell, J. (2009). Research design, qualitative, quantitative, and mixed methods approach (3rd ed.). New Delhi: Sage Publication.

[7] Creswell, J. (2007). Qualitative inquiry and research design (2nd ed.). New Delhi: Sage publication.

[8] Denzin, N. K., \& Lincoln, Y.S. (2005). The hand book of qualitative research ( $2 \mathrm{nd}$ ed.). Thousand Oaks, CA: Sage.

[9] Flick, U. (2009).An introduction to qualitative research. India: Sage.

[10] National Research Council, (1989). Everybody counts: A report to the nation on the future of mathematics education. Washington, D. C.: National Academy Press.

[11] Patton, M. Q. (1999). Qualitative evaluation and research methods. USA: SAGE.

[12] Vygotsky, L. (1978). Mind in society: The development of higher psychological processes. Cambridge, MA: Harvard University Press. 